\title{
La extensión en la currícula desde la perspectiva docente en Odontología Social de la Universidad Nacional de Rosario
}

\author{
Andrea Maino \\ andreacmaino@gmail.com
}

\section{Aníbal Díaz}

anibalfs@hotmail.com
Docentes investigadores de la Facultad de Odontología. Universidad Nacional de Rosario, Argentina.
Integración de la docencia y la extensión /

Intervenciones

RECEPCIÓN: 24/06/16

ACEPTACIÓN FINAL: 10/10/16

\section{Resumen}

Este trabajo apunta a reflexionar sobre un diseño curricular de la cátedra de Odontología Social de la Universidad Nacional de Rosario que desde su comienzo y hasta la actualidad está atravesado por la extensión universitaria. Por lo tanto, estamos hablando de un escenario complejo donde cada componente de ese diseño nos obliga a repensar y poner a prueba el conocimiento académico, lo interdisciplinario y la pluralidad de las profesiones en la formación de los futuros odontólogos en lo relacionado a las prácticas de promoción de la salud. Este análisis busca problematizar, resignificar prácticas de enseñanza y posibilitar otras formas de aprendizajes donde el sujeto es colectivo. La relación tiempo/ cobertura curricular nos interroga sobre el valor de las propuestas que remiten a la extensión en términos de contenidos a abordar y profundidad de su tratamiento. Por eso es factible pensar en estrategias de planificación con los estudiantes de manera que lo sientan como propio.

Palabras-clave

- Extensión universitaria

- Diseño curricular

- Programas comunitarios

- Promoción de la salud

\section{Resumo}

Este trabalho tem como objetivo refletir sobre um currículo da disciplina Odontologia Social da Univeridade Nacional de Rosario, que desde o seu início e até agora é atravessado pela extensão universitária. Portanto, estamos falando de um cenário complexo onde cada componente desse projeto nos obriga a repensar e testar o conhecimento acadêmico, interdisciplinar e a pluralidade de profissões na formação dos dentistas do futuro a respeito das práticas de promoção da saúde. Esta análise procura problematizar, ressignificar práticas de ensino e permitir outras formas de aprendizagem em que o indivíduo é coletivo. A relação tempo/cumprimento do currículo nos interroga sobre o valor das propostas que referem à extensão em termos de conteúdos a abordar e profundidade do seu tratamento. Por isso, é possível pensar em um planejamento de estratégias com os alunos para eles o sentirem como próprio.

Palavras-chave

- Extensão universitária

- Currículo

- Programas comunitários

- Promoção da saúde
Para citación de este artículo

Maino, A. y Díaz, A. (2016). La extensión en la currícula desde la perspectiva docente en Odontología Social de la Universidad Nacional de Rosario. En Revista +E versión digital, (6), pp. 292-297. Santa Fe, Argentina: Ediciones UNL. 


\section{Introducción}

A partir de la Reforma Universitaria de 1918 se propone la democratización del conocimiento científico y la promoción del acceso a la educación superior con el fin de reducir las desigualdades sociales y, en el contexto del Estado-nación emergente, reforzar la ciudadanía y la sociedad civil en la democracia.

Al interior de ese ideario, la extensión universitaria se incluye con el fin de fortalecer los lazos con la sociedad a través de la articulación teoría y práctica en la formación de los graduados universitarios con sentido social crítico.

Desde esa época hubo diversidad de experiencias, pero hoy en día Camilloni plantea que:

"Las misiones de docencia, investigación y extensión deben estar entretejidas. La investigación en tanto permite reconocer, diagnosticar e identificar las causas de los problemas sociales y programar con eficiencia las mejores soluciones. La docencia debe formar a los estudiantes y graduados que estén en condiciones de efectuar una efectiva intervención en el campo social profesional o no profesional y facilitar la relación teoría-praxis-teoría como dispositivo de formación. En ambos casos con el fin de realizar las acciones sociales directas que contribuyan a la solución de los problemas sociales e individuales". (2010:77)

A partir de 1978, la Organización Mundial de la Salud (OMS), y en la década de los '80 la Organización de Facultades y Escuelas de Odontología de la Unión de Universidades de América Latina, promovieron en la formación de grado de los odontólogos la adquisición de competencias que incluyeran prácticas de servicio e investigación.

El advenimiento de la democracia permitió crear en todas las Facultades de Odontología del país asignaturas que incluyeron actividades de extensión. La Facultad de Odontología de la Universidad Nacional de Rosario incorporó en el plan de estudio en 1985 un Departamento de Odontología Social, Preventiva y Sanitaria, hoy Área, con un grupo de asignaturas cuyo objetivo era la formación de profesionales no solo científica y técnicamente capacitados sino con un sentido social y humanístico.

En 1986 comenzó a funcionar la cátedra Odontología Social III, asignatura de la formación de grado de la carrera, con el Programa de Promoción de la Salud Bucal en la comunidad como actividad principal del programa académico. Por lo tanto, la curricularización de la extensión universitaria se realiza desde ese año.

Este trabajo apunta a analizar, desde una perspectiva docente, aspectos de los programas de la asignatura con el objetivo de reflexionar sobre las prácticas de extensión en la formación de los estudiantes universitarios.

\section{Breve descripción de la asignatura}

Los estudiantes que cursan la asignatura anual, con una carga horaria de 4 horas semanales, están en $3^{\circ}$ año de la carrera. Las prácticas en extramuros constituyen una parte prioritaria para la vinculación de la Facultad con la comunidad. El Programa se desarrolla en escuelas primarias públicas y privadas de los distritos norte, centro, oeste y sur de la ciudad de Rosario, provincia de Santa Fe, Argentina, según los lineamientos de la Estrategia de Atención Primaria de la Salud.

La experiencia comprende el trabajo de los estudiantes en contextos escolares y el aprendizaje de contenidos se realiza simultáneamente a las tareas de extensión. La evaluación legitima el proceso formativo en el proyecto didáctico de la cátedra y de la institución, teniendo como marco un perfil de ciudadano formándose como profesional ligado al contexto social. Los criterios epistemológicos se validan desde un modelo de salud determinado por los procesos históricos y sociales que incluyen todas las dimensiones de las condiciones de vida.

De allí que los contenidos conceptuales refieran a temáticas vinculadas a la Estrategia de Atención Primaria de la Salud, Promoción y Educación para la Salud y Epidemiología. Los mismos se enseñan y aprenden en los trabajos prácticos y clases teóricas. 
El programa académico (en adelante PA) de la asignatura tiene como objetivos generales formar a los estudiantes universitarios sobre conocimientos y prácticas de salud bucal correspondientes al primer nivel de Atención Primaria de la Salud en un marco de docencia, extensión, investigación, que permitan acciones sobre la realidad sanitaria de manera crítica y eficiente.

El Programa de Promoción de la Salud Bucal (PPSB) que se lleva a cabo en las escuelas consta de objetivos específicos, que son:

- Lograr la adhesión del escolar al Programa preventivo de la cátedra.

- Fomentar que los niños construyan nociones sobre la placa microbiana, sus relaciones y consecuencias, a través de intervenciones pedagógicas personalizadas y colectivas.

- Lograr que apropien prácticas de autocuidado sobre dieta, utilización de fluoruros y cepillado dental para prevenir caries dental y enfermedad periodontal.

- Propender a que los padres y maestros participen en dicho proceso acompañando las acciones y que apropien este conocimiento como efecto multiplicador.

El desarrollo del programa en la escuela se plantea sobre la base de un componente educativo y un componente preventivo. El componente educativo se organiza a partir de técnicas pedagógicas activas personalizadas y grupales que son enseñadas en el aula a los estudiantes universitarios.

Estas técnicas se centran en recuperar saberes y representaciones sociales sobre la salud bucal de los escolares: valores sobre el cuerpo, en este caso la boca, los dientes, creencias y políticas de higiene intrafamiliares, hábitos, prácticas y patrones alimentarios, y a partir de allí tratar de construir las estrategias de divulgación que la ciencia nos ofrece y viabilizar las posibilidades de los participantes para mejorar sus condiciones de vida.

Los aspectos educativos dirigidos a la comunidad durante la implementación del Programa se estructuran a partir del consentimiento parental.

El trabajo en la escuela consta de los siguientes pasos:

- Encuentro con los grupos: se hacen actividades lúdicas para formar las parejas estudiante-escolar.

- La tarea personalizada comienza con una entrevista basada en las técnicas de relación odontólogo-paciente niño, facilitadoras del espacio de confianza necesario para alcanzar las metas diagnósticas, clínicas y educativas.

- El cierre del Programa se organiza con actividades lúdicas, dramáticas y/o atravesamientos curriculares en el aula planificadas en conjunto con los docentes de la escuela.

- Reuniones y/o comunicación a los padres a través de notas o cartas.

- Georreferenciación a los centros de salud más próximos para la atención odontológica.
El componente preventivo del programa gira en torno al tratamiento de la placa microbiana determinante en los procesos de enfermedades bucales más prevalentes, como la caries y la enfermedad periodontal. Por lo tanto, se realizan prácticas que analizan a través de los indicadores las variables de riesgo: dieta, acumulación de placa bacteriana, calidad de la remoción mecánica de la misma, diagnóstico de la morfología dentaria. También se hacen tratamientos con fluoruros tanto para la remineralización de procesos de caries incipientes como para acelerar la maduración de las piezas recién erupcionadas.

La evidencia científica acumulada nos muestra que la probabilidad de enfermar puede disminuirse si se incorporan prácticas que tendrían que realizarse cotidianamente, tales como la remoción mecánica de la placa bacteriana a través del cepillado dental con pastas fluoradas y el control sobre la ingesta de azúcares.

El siguiente cuadro muestra la articulación entre ambos programas:

\begin{tabular}{|c|c|}
\hline Actividades & Lugar de cursado \\
\hline Entrenamiento clínico en el trabajo práctico y clases teóricas & Facultad \\
\hline $\begin{array}{l}\text { Contacto con la institución. Coordinación con directivos } \\
\text { y docentes. Aplicación del PPSB: ficha de cada paciente } \\
\text { con diagnósticos de índices de placa bacteriana, proceso } \\
\text { de salud-enfermedad-atención dental, registro de dieta y } \\
\text { fluorterapia. Trabajo pedagógico personalizado. } \\
\text { Retrabajo teórico constante del PA }\end{array}$ & $\begin{array}{l}\text { Escuelas públicas } \\
\text { y privadas. }\end{array}$ \\
\hline $\begin{array}{l}\text { Evaluación de contenidos teóricos y de casos simulados } \\
\text { de ambos programas }\end{array}$ & Facultad \\
\hline Intervenciones grupales educativas & Escuelas \\
\hline $\begin{array}{l}\text { Foro y clase final con información epidemiológica } \\
\text { y devolución por medio de un escrito a las escuelas }\end{array}$ & Facultad \\
\hline
\end{tabular}

El PA se evalúa con parciales individuales que poseen un eje articulador de los contenidos de la asignatura.

Al finalizar el PPSB se construye un trabajo escrito de producción grupal con análisis descriptivos y observaciones registradas de las actividades educativas realizadas, el cual es requerido una vez terminados los trabajos prácticos.

El foro como técnica pedagógica produce la socialización y circulación del conocimiento alrededor del desarrollo del Programa. Cada comisión reconstruye y presenta las prácticas realizadas durante el trabajo en la escuela. Éstas son: sistematización de entrevistas personales a los escolares, registro de intervenciones educativas grupales, atravesamientos curriculares escolares e intervenciones institucionales. Los estudiantes se contactan así con herramientas de investigación provenientes de metodologías cualitativas etnográficas: observaciones participantes y entrevistas. De este modo, el foro permite socializar la información de cada comisión a partir de la sistematización y análisis de lo trabajado. 


\section{6}

el foro como técnica pedagógica

produce la socialización y circulación

del conocimiento alrededor del

desarrollo del Programa.

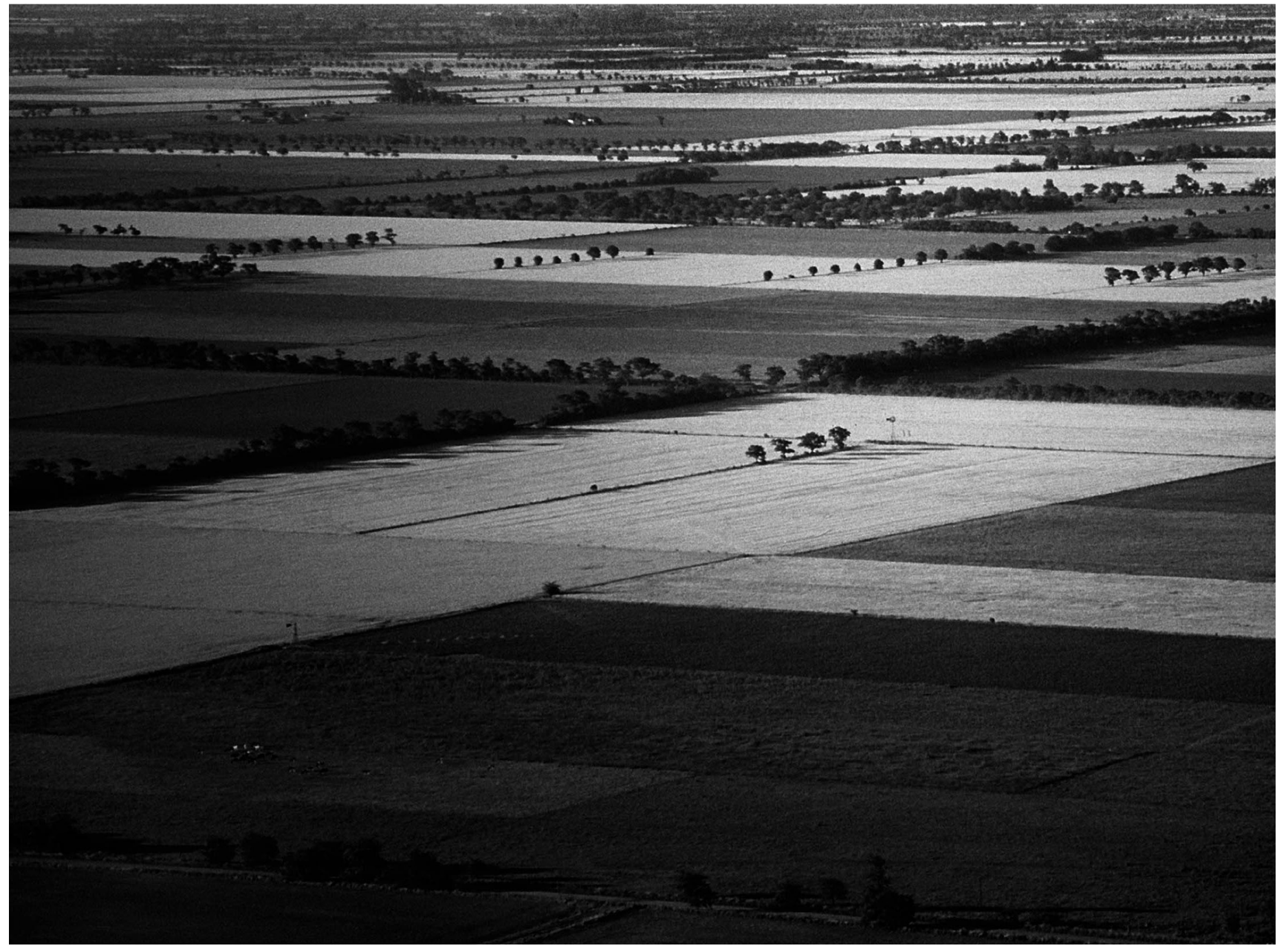

(c) Oscar Dechiara 


\section{en la evaluación se observa una dicotomía en el desempeño, donde se presentan a menudo estudiantes con habilidades, destrezas y conocimientos teóricos, pero con un bajo compromiso en el trabajo comunitario y a la inversa}

Los diagnósticos de caries dental tomados individualmente se transforman en datos estadísticos para construir perfiles epidemiológicos de la población escolar en un análisis transversal. Esto se expone en una clase teórica al final del ciclo y es material de estudio evaluable en el último parcial.

\section{Reflexiones desde la práctica docente}

Desde nuestra mirada, analizamos distintas fases de los trabajos prácticos que ameritan ser repensados.

Los trabajos prácticos realizados en la Facultad priorizan el entrenamiento preclínico, y estas tareas de diagnóstico se tornan lentas ya que todos los estudiantes hacen esa experiencia que se vincula a la práctica odontológica tradicional y restan tiempo para la planificación de las actividades de educación para la salud. El problema es que lo citado arriba se refleja en el trabajo en las escuelas en tanto opera como obstáculo en los aprendizajes de los estudiantes acerca de la función de los dispositivos de juego, plástica o dramática vinculados a la realidad social de los escolares. Ya en extramuros, en el trabajo clínico los estudiantes observan, registran diagnósticos y construyen índices vinculados a las fases reversibles de caries donde es primordial la intervención para anticipar la enfermedad. Este paso es importante para que las acciones de demostrar y hacer con los pacientes sean enseñadas con el objetivo de proteger la salud por medio de la incentivación del cuidado, y aquí es donde el conocimiento académico científico debe ser divulgado y donde se da la praxis. Sucede que ese encuentro con la práctica nueva es tan shockeante que hace que la mayoría quede atrapada en lo puramente técnico.

El cursado de otras asignaturas clínicas paralelas también tiene un efecto de sobrecarga para los estudiantes y les dificulta centrarse en la tarea.

En la evaluación se observa una dicotomía en el desempeño, donde se presentan a menudo estudiantes con habilidades, destrezas y conocimientos teóricos, pero con un bajo compromiso en el trabajo comunitario y a la inversa.

El estudiante adquiere un rol pasivo al no implicarse en actividades de planificación, organización y gestión del PPSB y esto recae en la responsabilidad de los docentes.

\begin{abstract}
4. Propuestas
Planteadas las cuestiones principales de la tarea docente, coincidimos con Nirenberg cuando sostiene que:

"Con referencia a los fundamentos epistemológicos, la participación de todos los que están involucrados en un determinado contexto permite un mayor conocimiento de esa realidad y sobre el modo más efectivo de intervenir en ella para introducir cambios o mejoras". (2006:58)
\end{abstract}

Es importante que esa participación al interior de los espacios educativos se construya en entornos amigables de respeto, diálogo y escucha. Tiene sentido cuando se permite a los que intervienen en los proyectos expresar sus inquietudes, opiniones y modos de entender las cosas, se escuchan las ideas y los cambios que se proponen y se posibilita tomar decisiones y sugerir nuevas acciones.

Desde el comienzo del ciclo lectivo, en la Facultad planteamos organizar el trabajo educativo desde antes de salir a la comunidad incorporando como contenidos material sobre técnicas de trabajo comunitario y comunicacional vinculadas a la extensión universitaria que incluyan la promoción y educación de la salud bucal y planificación estratégica para alcanzar modos de participación más eficaces con el escolar, la familia y los docentes. También pensamos que es relevante la tarea de registro de todas las instancias de las intervenciones porque eso hará factible construir protocolos de acción y evaluar a posteriori las prácticas y los posibles cambios.

Con respecto a la gestión de las distintas actividades del PPSB, el propósito fomentar la participación activa de los estudiantes desde el primer contacto con los maestros hasta las comunicaciones a la familia y a la institución escolar. Y al finalizar el Programa, la devolución a la institución a través de un informe en una instancia que se organice como una actividad formal en el que estén convocados todos los actores.

En el desarrollo de los trabajos prácticos, el docente que va acompañando los procesos de aprendizaje personalizado debe generar un espacio de socialización de las tareas realizadas para que haya circulación y democratización del saber, transformando espacios curriculares en abiertos y flexibles. 


\section{la formación los lleva a consumir contenidos que son adquiridos por instancias de transmisión o imitación de modelos y donde se produce una gran desunión entre lo cotidiano y el saber científico}

Pensamos que la elaboración de portfolios como recurso didáctico, donde los estudiantes vuelquen sus registros de forma escrita, permitirá objetivar los aprendizajes sobre la gestión del PPSB con los escolares y al mismo tiempo se constituirá en materia prima para los informes que se llevan al foro de intercomisiones al final del cursado. Esta metodología posibilitará en un futuro narrar la trayectoria del PA ya que su propia historia amerita ser objeto de investigación.

La construcción de los datos epidemiológicos admite una lectura de los procesos de salud-enfermedad-atención de caries de los grupos escolares, no tiene valor de muestra poblacional pero sí se pueden considerar comportamientos y tendencias de este proceso. Hasta ahora se analizan datos transversalmente por escuela pero se propone, para observar la trayectoria de la salud oral individual y colectiva, construir un análisis epidemiológico longitudinal.

Según Dabas (2006), la participación tiene diferentes gradientes que van desde la trasmisión de información a los padres con asistencia o sin ella, consultas, hasta propuestas sobre mejores modos de conexión para un protagonismo responsable que les permita a las familias tomar decisiones. Con respecto a la comunicación y la participación de las mismas en el PPSB, la modalidad de reunión realizada en los comienzos se tornó difícil de sostener por la baja concurrencia de los padres, y con el tiempo se optó por el envío de notas o cartas para comunicar cuestiones inherentes a sus hijos y donde también se informa sobre la georreferenciación de los niños a los centros de salud más próximos a donde habitan para concretar la atención odontológica. Además, se está contemplando incorporar el uso de redes sociales para mejorar la comunicación, según los recursos informáticos disponibles en cada escuela. Si bien la extensión viabiliza transformaciones en la comunidad, va en doble mano con la formación educativa de los estudiantes atravesados por los tiempos curriculares de la asignatura. $Y$ a pesar de este límite, la fortaleza del PPSB es la permanencia en las instituciones educativas con un rango que se extiende entre 1 a 18 años, por lo que, si hay un aspecto definitorio de la extensión universitaria, desde nuestra perspectiva, no son las intervenciones aisladas sino el desafío de dejar capacidades instaladas.

\section{Una apertura para el cierre}

El presente trabajo nos ha permitido describir los problemas que suceden en una asignatura cuyas actividades transitan entre dos programas que se tensionan entre sí, mediados por el recurso más escaso en educación que es el tiempo.

Ante el predominio de los enfoques clásicos en las aulas, pocas veces los universitarios participan de las actividades auténticas propias de cada cultura disciplinar. La formación los lleva a consumir contenidos que son adquiridos por instancias de transmisión o imitación de modelos y donde se produce una gran desunión entre lo cotidiano y el saber científico.

Reconocemos que en la formación de los estudiantes que enfrentan prácticas al mismo tiempo que las van estudiando y que posteriormente formarán parte de su trabajo, en un contexto social que se plantea como incierto, cambiante, complejo y desigual, radica un proceso único que posibilita la construcción del conocimiento, la enseñanza y el aprendizaje.

Este proceso solo se puede construir en un marco de extensión universitaria que admita la democratización del conocimiento académico y la participación efectiva de la comunidad en una ida y vuelta en el cual ambas se fortalecen en la interacción y el intercambio.

\section{Referencias bibliográficas}

Camilloni, A. W. de (2011). La inclusión de la Extensión Universitaria en la formación de los estudiantes de la Universidad Nacional del Litoral. Revista de Extensión Universitaria $+E$, 1(1). Santa Fe: Ediciones UNL. Recuperado de https:// bibliotecavirtual.unl.edu.ar/publicaciones/index.php/Extension/article/view/449 (28/4/2014)

Dabas, E. (Comp.) (2006). Viviendo redes. Experiencias y Estrategias para fortalecer la trama social. Buenos Aires: Ciccus.

Nirenberg, O. (2013). Formulación y Evaluación de Intervenciones sociales. Buenos Aires: Noveduc. 